June - 2007

\title{
m-Learning: Positioning educators for a mobile, connected future
}

\author{
Kristine Peters \\ Flinders University \\ Australia
}

\begin{abstract}
Mobile learning is variously viewed as a fad, a threat, and an answer to the learning needs of time-poor mobile workers, so does it have a place in delivering mainstream learning? Based on a 2005 comparative research project, commissioned by the Australian Flexible Learning Framework, the paper reports on research into Web-based information about the use of mobile technologies for commerce and learning, which was then tested through 29 interviews with manufacturers of mobile devices, businesses and education providers. The research found that mobile technologies were in common use in some commercial sectors, but their use purely for learning was rare. m-Learning lends itself to new methods of delivery, however, that are highly suited to the 'just enough, just in time, and just for me' demands of 21st Century learners.
\end{abstract}

Keywords: Communications; demand; flexible learning; m-Learning; m-technology; online learning; SMS; teaching; training delivery; trends

\section{Introduction}

The distinguishing feature of our society at the beginning of the 21st Century is the rapid rate of technological and social change. Technological advancements that allow fast communications and information processing are supporting new social patterns. As a result, communities are no longer only based on geographical proximity, and new 'tribes' (Rheingold, 2002) are developing and disbanding according to interest, work patterns, and opportunity.

Mobile information and communication technologies are important enablers of the new social structure. We are experiencing the first generation of truly portable information and communications technology (ICT) with the relatively recent advent of small, portable mobile devices that provide telephone, Internet, and data storage and management in products such as: $i$ Mate, O2, Palm, HP, and Bluetooth (all registered trademarks) that combine mobile telephony, removable memory chips, diaries, email, Web, basic word processing and spreadsheets, and data input, storage, and transfer.

The communication and data transfer possibilities created by mobile technologies (mtechnologies) can significantly reduce dependence on fixed locations for work and study, and thus have the potential to revolutionise the way we work and learn. A mobile, connected society, however, creates new training delivery challenges. Individuals expect training that is 'just in time, 
just enough and just for me' (Rosenberg, 2001), and that can be delivered and supported outside of traditional classroom settings (Peters \& Lloyd, 2003).

In order to support a strategic response to the opportunities and demands of mobile learners, the education and training sector needs to be informed about the actual use of mobile devices at work and in workplace learning, and about potential future trends in mobile learning. This paper is based on research commissioned in 2005 by the Australian Flexible Learning Framework, which aimed to provide a better understanding of the separation between real opportunities for mobile learning using small electronic communication devices (m-Learning) and the hype surrounding the introduction of new technologies. The research provided an overview of popular media coverage of the use of m-technologies and m-Learning, and compared this with the findings from a small number of qualitative interviews. A short review of the academic literature was conducted, but the need for a contemporary perspective meant that there were very few research articles on m-Learning available and, therefore, limited reference has been made to peer-reviewed academic publications. As the key aim of the research was to separate the 'hype' from the 'reality,' the focus was on providing a snapshot of mobile technologies and their use in 2005. Indeed, a completely new generation of mobile communication devices (3G cell or mobile telephones) became available during the six months of research for this project, thus illustrating the challenge of maintaining publishing currency in a fast-moving field.

\section{An Introduction to m-Learning}

The availability of mobile and wireless devices is enabling different ways of communicating. Mobile communications are no longer restricted to companies that can afford large investment in hardware or specialised software. Individuals now have easy and inexpensive access to mobile telephony, and the cost of mobile access to the Internet is steadily reducing. Mobile technologies have enabled a new way of communicating, typified by young people, for whom mobile communications are part of normal daily interaction, who are 'always on' and connected to geographically-dispersed friendship groups in 'tribal' communities of interest.

This research aimed to test the validity of news and information media comment on mobile communications, which indicated that the 'always on' generation is, to a large degree, driving development of consumer communication technologies - as can be seen from the rapid adoption of Short Message Service (SMS). SMS is texting via mobile phones - also known in some countries as 'cell phones' - which was unexpectedly adopted by the 'text' generation, and became a pervasive communication tool in its own right. The popular and business press also reported that mobile and professional employees are driving the convergence of Personal Data Assistants (PDAs) and telephony, and of 'smart' phones (that provide both telephone and Internet services) through their demand for greater integration of online information, data management, and voice, image, and text communications. The same source shows that industries with specialist needs (such as mobile barcode readers in supermarkets and electronic courier delivery confirmations) are another significant driver of mobile product development.

The three drivers described above - consumers (particularly young consumers), mobile professionals, and specialist industries - have created strong demand, which is reflected in the increasing rapidity of development of new mobile communication and data management technologies. The trend toward convergence of applications, the ubiquitousness of mobile phones, and the continuing demand for smaller, more powerful devices indicates that mobile technologies are, indeed, mainstream. Is their use for learning, however, following the same trend? 
The advent of mobile technologies has created opportunities for delivery of learning via devices such as PDAs, mobile phones, laptops, and PC tablets (which are laptops designed for a handwriting rather than a keyboard interface). Collectively, this type of delivery is called mLearning. While m-Learning can be thought of as a sub-set of e-Learning (which is Web-based delivery of content and learning management), the emerging potential of mobile technologies tends to indicate that m-Learning, while mostly situated within the e-Learning framework, also has links directly to the 'just enough, just in time, just for me' model of flexible learning (see Figure 1), and is therefore just one of a suite of options that can be adapted to suit individual learning needs.

Figure 1. The 'just enough, just in time, just for me’ model of flexible learning

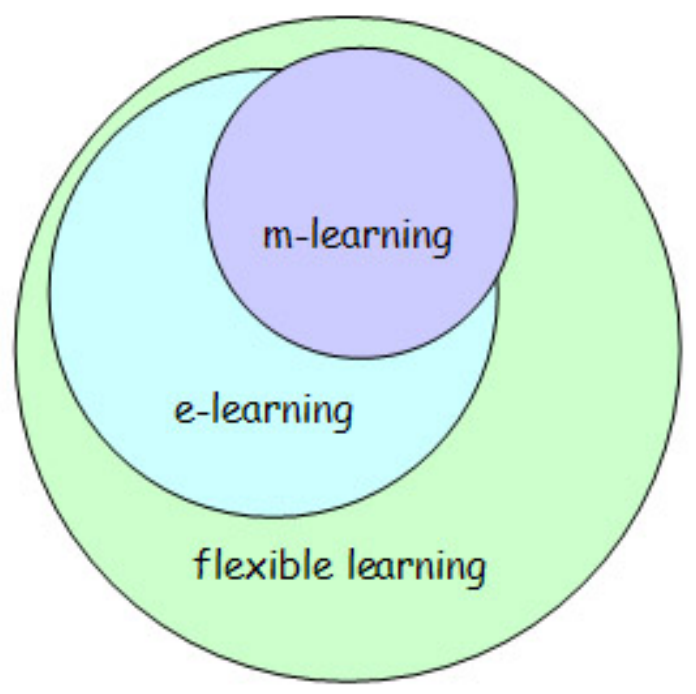

\section{Literature Review}

Much of the documented evidence of m-Learning in this paper has been sourced from www.flexiblelearning.net.au, the Australian website that supports the flexible delivery of, and practice improvements in, vocational education and training. While peer-reviewed academic journals are a preferred source of material, the constraints of this research project (primarily the requirement to find out what was actually happening at the time the research was undertaken in 2005), and the funding body perspective (that m-Learning projects undertaken under the Australian Flexible Learning Framework should inform the research) determined that the outcome would be a report that provided guidance to future scholarly investigation, rather than one that contributed to the formal literature. The following discussion, therefore, is largely based on the informal literature.

\section{m-Learning as a Practical Training Solution in Mobile Workplaces}

Klopfer, Squire, Holland and Jenkins (2002) propose that mobile devices (handheld computers) 'produce unique educational affordances', which are:

a) Portability 
b) Social interactivity

c) Context sensitivity, the ability to 'gather data unique to the current location, environment, and time, including both real and simulated data'

d) Connectivity, to data collection devices, other handhelds, and to networks

e) Individuality, a 'unique scaffolding' that can be 'customized to the individual's path of investigation’

The 2005 Web search found that organisations of all sizes were using mobile devices for learning because technological advances meant that there was no longer the need for large infrastructure and support costs, and even small enterprises could deliver mobile learning simply by structuring learning around Web-based content that could be accessed from Web-enabled mobile devices.

Work by Marcus Ragus (2004a) for an Australian Flexible Learning Framework New Practices in Flexible Learning Project, tested the use of PDAs in four different work environments: botanical gardens, nursing home, food and hospitality, and workplace assessor. The Royal Tasmanian Botanical Gardens trial found that simultaneous personal development for staff in separate organisations was possible, and that such strategies can be designed and targeted for a mixed audience comprising managers, teachers, ground staff, and apprentices. The nursing home trial used integration of PDAs into the general on-site training of the nursing staff through the use of simple resources created with Microsoft PowerPoint (Ragus, 2004a). The food and hospitality sector trials grew from a need to develop interesting, interactive resources for use by trainee bar and beverage staff, and demonstrated the application of an existing PDA image program to create a learning resource (the importance of this project was that special software was not required). Workplace assessment practice trials were undertaken within the horticulture sector, the aim of which was to use PDAs and a peripheral plug-in camera to capture evidence of assessment at remote workplaces where it is imperative that both assessors and learners are able to operate with a high degree of flexibility for delivery of learning, and for the materials and equipment required for the work (Ragus, 2004a).

Many other m-Learning applications were identified, perhaps best exemplified by Deviney and von Koschembahr (2004) who describe the situation in a major electronics retailer, which used a mobile learning program to train new sales associates. In this organisation, new employees had previously spent several hours off the job reading materials or accessing a learning portal to study products; because learning was abstracted, the quality and usefulness of this type of learning was limited. Using m-technologies, the retailer was able to equip staff with a hand-held PDA and barcode scanner, and employees were able to learn about products on the sales floor where the learning was situated within the context of their job.

Lundin and Magnusson (2003, p. 19) saw mobile technologies as a solution to the fragmentation of a mobile workforce: "within a distributed and mobile workforce opportunistic meetings with colleagues are naturally less likely to occur than if workers are co-located" (citing Bellotti and Bly, 1996), where mobile technologies provided synchronous communications that enabled connectivity between workers in real time and thus overcame many of the barriers created by mobility. 


\section{m-Learning and the Teacher-Student Relationship}

The digital age has created a new relationship between teachers and learners. Research conducted by the London School of Economics found that children are typically the Internet experts in the family, and described this situation as a "lasting reversal of the generation gap" (Smithers, 2003, I 1 ). This reflects the challenges facing education and training providers who are steeped in traditional delivery styles when confronted with digitally literate students, where, rather than simply receiving and memorising the wisdom of their elders, which has been the tradition for millennia, students are now demanding training that meets their specific information needs. Dale Spender, renowned feminist scholar, writer, and consultant, whose work includes exploration of the social effects of new technologies, observed that there is a divide between traditional teaching techniques and the attitudes of contemporary youth. Spender's (personal communication, Sept., 30 2005) observation reinforces the divide between traditional teaching and the attitudes of contemporary youth:

Eight year olds think there's something wrong with their teachers. Don't teachers know that heads are unreliable places? That's what the save key is for. Even if you do store things in your head, you can't ever find them again.

m-Learning also creates learning opportunities that are significantly different to those provided by e-learning (at a desktop) or paper-based distance learning. Chen and colleagues (as cited in Bridgland \& Blanchard, 2005) describe the principal considerations to be taken into account when designing m-learning delivery:

- The urgency of the learning need

- The need for knowledge acquisition

- The mobility of the learning setting

- The interactivity of the learning process

- The situatedness of the instructional activities

- The integration of instructional content

Young people do not experience geographical place and time as barriers (Fannon, 2004). Fannon's research found that although some older learners used their mobile phones to arrange face-to-face meetings to work on assignments or discuss learning issues, younger learners were more comfortable with the thought of using mobile phones for learning, and almost half (45\%) of the research group were prepared to use Internet-enabled telephones as their only tool for learning. The challenges of creating learning to be delivered via mobile phones are not easily solved by teachers, however, many of whom are recent 'migrants' to the digital world (Prensky, 2001).

Dale Spender (personal communication, 2005) expressed concern about the ability of teachers to understand and respond to digital learning opportunities, citing the aging teacher population and their lack of comfort with digital ICTs, the focus on 'teaching and memorising' as opposed to 'learning and seeking information,' and reliance on 'doing it by the book.' This approach is fundamentally different to the approach of 'digital natives,' Prensky's (2001) term for those born in the digital age for whom ICT is second nature, for whom 'not knowing is an impetus to find out,' and who believe that 'if you need to use the manual, the product is no good'. Spender's position is reinforced by Aquino's (n.d.) observation: 
Teaching has a long established culture of individualism and secretiveness and many teachers are very challenged by the need to work collaboratively with technicians, Web developers, instructional designers and programmers to deliver successful Web-based education (p. 9).

Many teachers are interested and able, however, to provide m-Learning content, learning management and support. The following examples illustrate how m-Learning is being used and supported:

- 'Environmental Detectives' is an example of an increasing suite of games designed for mobile devices. Students played the role of environmental engineers presented with a scenario in which the spread of a toxin was simulated on a location-aware Pocket PC equipped with a Global Positioning System (GPS). The Pocket PC allowed students to investigate a toxic spill by sampling chemicals in the groundwater and responding to different variables programmed by the teacher (Klopfer et al., 2002). The use of virtual characters within the program allowed students to gain an experience that is close to real life, provided context, significantly reduced abstaction, and resulted in a blurring between the game and real life. For instance, in an unanticipated event, one group stopped in the middle of the game and used Google to search for clues. The strategy of accessing other outside resources was not only acceptable within the rules, it was perhaps advisable, given the time constraints and use of authentic chemicals and historical data. Students were able to locate information quickly and easily on Google, suggesting the role that a tool such as Google can play in transforming an educational experience.

- In designing Melbourne Law School's new building (built in 2002), a key feature was the provision of wireless networking that allowed students with mobile computing devices to access course material and conduct searches of legal databases during class, thus expanding the depth of the discussion and the learning experience for the student (Hartnell-Young \& Jones, 2004).

- The medical field has applied mobile technology to remote learning in rural health education. Hartnell-Young and Jones (2004) described the use of Tablet PCs that helped students to capture and store confidential patient information, and deliver just-in-time information on clinical problems. Students kept a reflective journal using their mobile device, which was later used as a reference for discussion with their instructors.

- Zurita and Nussbaum (2004) demonstrated the effectiveness of handheld devices in teaching first-grade children to construct words from syllables. In a month-long controlled experiment, children who were supported with technology had significantly higher word construction test score improvements than children who were using paperbased activities.

These examples of good practice, and of m-Learning 'in the field' are by no means isolated. The generic uptake of m-Learning, however, is still some way off, and the application of m-Learning requires a new paradigm. Indeed, as Aquino (n.d., p. 5) reflects, learning is ". . . emotionally based and consistently and powerfully influenced by the learner's culture and experience" and traditional teaching methodologies that are "essentially passive, theoretical, text-based and linear" will fail to engage young learners and fail to deliver the skills needed for future social and work environments. 


\section{m-Learning and Learning Cultures in Workplaces}

Is the promise of mobile technologies as a trigger to generate learning cultures realistic? And is m-Learning any more likely to increase interest in learning than any other form of delivery? Articles about the link between mobile technologies and learning organisations appear to fall into three categories:

1. A database focus that captures organisational knowledge

2. A human systems focus that allows synchronous communication and information sharing at the worksite

3. A learning development focus that suggests that learning about new technologies generates a more general drive for learning

The database focus has, to a large degree, become the accepted wisdom in organisations that use structured processes to collect, codify, and manage knowledge. Mobile technologies have the potential to collect a greater range and percentage of data, through recording of activity on the device (and subsequent analysis of the patterns of access to specific information or information sources) and through the reduction of paper-based records as electronic systems replace paper in the field.

The capacity of mobile technology to deliver synchronous communication and knowledgesharing can provide benefits to human (or soft) systems. Evidence of these benefits has been reported by Ragus (2004a), who found that m-Learning encouraged simultaneous personal development, such as networking and socialisation, outside of normal working groups - an unexpected, and positive result of the m-Learning trials.

The 'learning tools leads to learning culture' concept is more tenuous and has received limited attention in the m-Learning literature. However, the industry participants in Ragus' (2004b) New Practices Project found that m-Learning had generated new ideas for the incorporation of technology in the workplace, which indicates an enthusiasm for further learning introduced through the m-Learning experience.

Brodsky (2003) looks at drivers in learning organisations and concludes that the trend toward customer self service (such as automated options for telephone enquiries, or online payment or registration of service needs) will result in changes to the nature of customer service training. Brodsky suggests that the automation of routine transactions means that the role of customer service or sales staff changes, there is greater need to manage complex transactions, with a higher level of knowledge and interaction skills and that, as a result, training technologies will become so intuitive that the technology will no longer be the focus, instead the focus will be on how the application serves the needs of the business.

The literature described a range of uses of m-technologies for learning, some of which were in the trial stages, and others where mobile devices are in common or daily use, and are accepted as a normal part of learning. To what degree did the experience of Australian businesses and education and training providers reflect the findings from the literature? This question will be answered in the next section that describes the research results. 


\section{Research}

The purpose of the research was to provide an indication of whether Australian businesses are actually using m-technologies and m-Learning in the ways portrayed by the popular media. Originally intended to form the basis of a discussion paper for vocational education practitioners, the research brief did not require rigorous investigation or statistically valid samples. This paper reports on the findings of that (limited) research, framed by the literature, using interviews to establish the status of m-technology use and m-Learning uptake. Interviews were conducted with 29 respondents, representing: Australian businesses that use mobile technologies; manufacturers of mobile devices and software developers for mobile applications; and educational and training institutions.

The following criteria were used to determine whether devices were within the scope of the research: 1). capable of providing electronic communication and/ or information functions; 2). small enough to be easily carried; 3). can be used (at least part of the time) without a physical connection to fixed power or telecommunications services.

The following section of the paper describes the method and findings.

\section{Method}

Based on the findings from the literature search, three survey instruments were developed: manufacturer/ software developer, business and educational provider. Four manufacturers/ software developers were interviewed: two large international corporations (Nokia and PalmAustralasia), and two developers of software for mobile devices. Six businesses were interviewed, including large national corporations, medium sized firms, and small companies. Nineteen educational providers $(n=19)$ were interviewed, representing universities, high schools, private training providers, TAFE (the largest public provider of vocational education and training in Australia), and industry skills councils (the organisations that determine the content of national vocational curriculum).

The manufacturer survey instrument contained questions about: the use of mobile technologies for business and personal purposes; product uses that were not an expected part of the product design; drivers of new product development (specifically whether designs responded to requests by particular customer demographic groups); future trends for mobile technologies; and whether mobile devices were being produced specifically for educational use. Interviews were carried out by the author's company, KPPM Organisational Strategists, during the period May to July 2005.

The business survey instrument investigated: mobile technologies used as part of 'normal business processes'; whether mobile technologies contributed to business efficiencies and greater productivity; the value of mobile technologies to the business; and the use of m-technologies for learning.

Education providers were asked: whether m-technologies were discussed by students and teachers; what (if any) mobile technologies were in use as learning aids; whether m-technologies presented opportunities for new types of delivery or management of learning; and the type of student most likely to use m-technologies for a variety of learning purposes (such as communicating with peers or teachers, doing research, or timeshifting lectures). 


\section{Results}

\section{Business interviews}

A search of the print media and Internet revealed a steady stream of new mobile technologies aimed at a wide range of markets. Small mobile communications and storage devices were advertised for applications as wide-ranging as: risk assessment, triage, fire inspection, bylaw enforcement, building inspection, city engineering, security, surveillance and military purposes. These findings were tested through the interviews with businesses, which revealed that (despite the low number of respondents), a range of technologies were used, with the most common being laptops, mobile phones, PDAs and portable media players.

An example of how m-technologies were being used in business was provided by South Australia's Department of Transport, Energy and Infrastructure, which was implementing mobile communications for traffic signal maintenance workers. This is what they had to say:

Field staff had previously been using laptops, but had to wait until they were back at the office to update data. The introduction of communications cards enabled real-time communication through automatic redirection of fault logs straight from signal switchboards to field worker laptops. This process also allowed the capture of fault and repair data, which needed to be recorded for legal reasons. Mobile phones were considered for this task, but did not have the bandwidth to deliver sufficient data at the required speed.

Has the use of mobile technologies increased business efficiency? Businesses saw significant benefits from mobile technologies. The following list shows common business efficiencies from the use of m-technologies:

- Flexibility, speed, and more efficient networking, which allows access to large numbers of staff throughout the world

- Provision of efficient customer service

- A more efficient working environment, with less manual paperwork - work can be done faster, more flexibly, and with greater levels of accessibility

- More efficient training, saving time to inform staff about new products and processes

- Improved storage and backup of data, with much of the risk removed

- $\quad$ Saving of time and money

- Creating greater responsiveness to change.

Respondents reported that these outcomes were based on carefully thought-through business cases that considered markets, productivity, professional development, staff morale, risk management, knowledge management, cost, and responsiveness to a dynamic operating environment:

If we moved offices again we would commit to 100 percent wireless network. It makes more sense as we have a lot of core infrastructure already in place. This would also allow flexibility to 
increase PDA use which would result in increased access to email from outside the office, and automatic synchronising of remote data with the server.

Laptops were the most commonly mentioned device for mobile learning.

The value of mobile technologies was further tested by asking scaled questions about business benefits in four categories: finance, staff satisfaction, competitive edge and business culture. The highest ratings were for financial and business culture, but all categories rated at least 4 out of 5 as can be seen in Table 1.

Table 1. Business benefits of m-technology use

\begin{tabular}{|l|c|}
\hline \multicolumn{1}{|c|}{ Category } & Mean rating \\
\hline $\begin{array}{l}\text { The value of mobile technologies in creating a business } \\
\text { culture that values new knowledge }\end{array}$ & 4.6 \\
\hline $\begin{array}{l}\text { The financial value of mobile technologies to the } \\
\text { organisation }\end{array}$ & 4.6 \\
\hline \begin{tabular}{l} 
The value of mobile technologies to staff satisfaction \\
\hline $\begin{array}{l}\text { The value of mobile technology in establishing a } \\
\text { competitive edge }\end{array}$
\end{tabular} & 4.1 \\
\hline \multicolumn{1}{|c|}{ [Scale 1= not important to 5= essential] } \\
\hline
\end{tabular}

Businesses saw the next evolution of mobile technology applications for their businesses to be:

- Greater choice in hardware, resulting in a better fit between commercially available devices and the needs of individual businesses

- More customers using phones, PDAs, Internet, and email to order and make bookings

- Blended training with an increased proportion of learning delivered on mobile devices

- Faster, more efficient technology as part of a normal work environment

- Simulated and interactive training using games to teach problem solving and resolve issues

- Convergence of technologies and increased use of devices that can do more than one thing

- Increase in wireless hotspots to provide improved access to the Internet from outside the standard work environment, so that workers are not restricted when travelling

- 100 percent mobile

As one responded noted: 
It's a great benefit to be totally mobile - efficient and faster - however at this stage it is not a core part of our business. It is important in terms of safety that we get the information out there quickly and efficiently. Moving towards more mobile technologies would be a really good influence in changing the whole culture of this business.

\section{Education and training interviews}

Interviews with the education and training providers showed that less than half engaged in discussions with students about the use of mobile technologies for learning, despite the high level student use of mobile phones. A public training provider commented:

The topic that is becoming more frequent is how to get access to learning without coming into the classroom, and what mobile technology could be used to receive and store information.

Approximately half of the educational providers said that the use of mobile technologies for learning was a frequent topic of discussion with teaching staff. Some of their comments were:

- M-technology is being discussed more because the organisation is forcing it to become an issue

- Change is happening, but the first task is to learn about and understand how to use the technologies

- The most common discussion is about the development of mobile technologies within industry

Providers were asked about student readiness for mobile technologies. The most common mobile technology is the mobile telephone, so it was interesting to see what the following seven providers thought about student readiness for using mobile phones for learning.

- Mobile phones are mainly used to SMS parents regarding attendance and other communications

- Students already have mobile phones and it would be good if they were used more for learning

- Students have mobile phones although PDAs are not as popular. Providers are less concerned with the device that students use, than with what they do with it

- Some colleges already use mobile phones for communicating with students using text reminders

- SMS is already in place but the opportunities to use it for learning have not been considered in great depth - implementation will largely depend on practicalities and cost

- $\quad$ Resourceful teachers are incorporating SMS because young people are using it anyway, it's a great motivational tool 
- m-Learning is ideally suited to adult education if it is used to extend the reach of programs. It allows students to get a response quickly, at all hours, they like the interactivity and the ability to receive a quicker response than they would via email

A number of educators mentioned that cost is a barrier; the following four quotes are good examples:

- Laptops enable students to dock into the student network, however these are not widely accepted because of cost

- More students would like laptops and wireless technology, but there is a cost constraint in providing the equipment

- If all students already owned laptops, PDAs, or mobile phones, it would be easier to use them for learning; but providers cannot ask students to buy them because the cost would exclude some people

- Teachers would like to use PDAs and laptops, but the problem is resources to develop materials and provide support, the infrastructure is lacking

How ready are students for m-technologies other than mobile phones? The five quotes below provide some telling clues:

- Students are already using laptops, but are looking for more wireless options

- Students are ready for SMS and PDA to access learning objects and assessment pieces

- $\quad$ PDAs are provided to students to do tests

- Students are ready for greater use of 3G mobile phones and pocket PCs/ organisers, which are already being used for communication because of their flexibility and portability

- $\quad$ Students use laptops for general learning, mobile phones for downloads from the Internet and general learning, and a few who travel long distances use MP3 players to download lectures

One regional provider found that students were not ready for mobile technologies, but felt that workplaces were ready.

Teacher readiness for mobile learning is seen as a barrier by a number of providers. The following three quotes are examples of this:

- It all depends on the teachers and some have not yet mastered desktop technologies! The teachers are a critical part of this, and some are not ready. Only a small percentage of classroom teachers use PDAs and they are mainly for personal use, although some have used them as a teaching tool 
- A recent survey of our teachers found that 2 percent had never turned on a PC, 5 percent could not burn to CDROM and there is no use of ICT for general teaching, although some ICT-based communications are done on an individual, personal basis

- Not a lot of teachers use mobile technologies. PDAs are an executive tool, although mobile phones are ubiquitous

On the other hand, others found mobile technologies to be beneficial. The following three quotes illustrate this:

- Mobile technologies are being developed for field work, primarily to communicate with the office

- We use mobile phones to edit our newsletter

- The availability of m-technologies presented opportunities for new types of delivery and management of learning.

Seven education and training providers reported that m-technologies:

- Make teachers think — the thought process is often hard to change and using new technologies seems to help

- Overcome geographic barriers, m-Learning removes the problem of locality and the requirement that students travel to access learning

- Offer greater flexibility for staff and students

- Allow learners to learn in the field, where and when they want. However, mobile phones are not a huge teaching tool, as the students use them mainly for social contact and do not want to use them as a learning tool

- Force providers to rethink the way that they teach: We need to break down the elements of the course into small packages based on mobile technology so that students can access portable learning, learning activities, and multiple choice games from their mobile units

- $\quad$ Provide a faster way of informing students (using SMS) and flexible delivery that is not bound to computer so we can engage across physical space

- Enable situated learning or learning in context, using phones with cameras/ video capabilities to enable students to capture their own material and instantaneously transfer to other students and lecturers. Mobile phones are also used as tools for group learning

Education and training providers were asked about learning outcomes. Their responses show that they understand the pedagogical opportunities provided by m-Learning, which is seen to:

- Help to break down the financial and mobility constraints of learning 
- Improve literacy through collection and provision of evidence for assessment portfolios

- Enable the use of digital story-telling to demonstrate competence

- Provide faster, more exciting ways of teaching, more flexibility, more mobility

- Allow for full qualifications to be delivered via mobile devices

In many organisations, m-Learning is yet to be structured into the curriculum; the following six quotes illustrate this:

- The uptake of m-Learning depends on the teacher and the curriculum coordinator

- It is experimental at moment, providers are looking at all ways to deliver subjects, so that students can choose how they would like to learn

- The education of school teachers about m-Learning needs to come first. Teachers need to understand the benefits of letting students use mobile devices for learning. At this stage, teachers are still very negative about students using mobile phones in the classroom other than for contacting parents at home time

- m-Learning needs to fit within a whole matrix of curriculum and assessment, the positioning of this mode of delivery needs to be thought through before it is implemented

- We are just starting to look at mobile technologies, which are regarded as a new area within e-Learning

- The uptake of the technology at the workplace is the prime driver of m-Learning

Only two respondents said that m-Learning was already in place in their organisations, and both were delivering learning to remote communities:

- m-Learning is not formally included in courses, but students would experience it in most subjects

- m-Learning is structured into remote teaching so that all students have access to learning without having to come into the campus. m-Learning provides financial savings because we don't have to provide physical space for all students. However, issues such as whether m-Learning allows higher quotas for courses and how to structure lecturers' pay are still to be resolved

\section{Manufacturers and software developers}

Because of the limited number of interviews with manufacturers and software developers, the findings have been grouped into the following:

- First, producers of hardware and operating systems often minimise costs and maximise effect through product development partnerships 
- Second, demand from consumers and businesses is the influence on the type of product being developed, with the common requests being: easier to use, smaller, faster, smarter, and greater security. This has resulted in advancements such as multiple security layers, Bluetooth, car and business kits, hands free and infrared/ data cables. When asked about the future applications or capabilities that are planned for existing products, the response was: 'smaller, faster, better, cheaper, and more wireless technology to send bigger files faster.'

What percentage of mobile technologies are purchased for business purposes and what percentage is purchased for consumer use? The following quote tells the situation:

- There is such a cross-over between personal and business use we're unable to tell them apart. Higher end products (i.e., Bluetooth or wireless, products with extra security, or products containing enterprise solutions) are marketed only to business clients, but the simplest phone can be used for business as well as personal purposes

Much is made of the potential of m-Learning, but what is actually happening from a developer perspective? The two following quotes illustrate the developers' insights:

- A flash-based mobile interface is now being produced for m-Learning, so that animated material can be used on mobile phones; the technology is now moving quickly to respond to the increasing speed of m-Learning uptake

- As an add-on to other modes of deliver, m-Learning will increase. But it won't replace other forms of e-education because screens are too small and hard to read, and if you make them bigger, the device isn't as mobile. m-Learning is most useful when it's in a mobile, field environment

\section{Conclusion}

The key features of mobile learning identified in this report are: its ability to provide learning that is 'just in time, just enough and just for me;' learning that is situated (typically in the field or at the workplace); and learning that is contextualised through mediation with peers and teachers. While mobile devices are making some types of learning easier to access, they have the potential to deliver the kind of learning that in past times could only be done with a knowledgeable tutor working on-site, alongside the student. Clearly tutors are too expensive to provide en masse, but mobile technologies provide the capability for training that can be tailored to the needs of the individual learner and diverse worksites.

Is this hype, or is it actually happening? Informal learning using mobile technologies is already embedded in our daily lives. Millions of Web-enabled phones are being used by learners (who may not be enrolled in formal courses) to seek information. Use of mobile phones, PDAs, and laptops in organisations is well-established, and interviews with employers indicate that mLearning, indeed, is occurring at the workplace, although the focus tends to be on business needs, rather than the technology used for delivery.

Many education and training providers recognise the benefits of mobile learning, but there appears to be limited adoption for educational use, which was attributed to: the age and ability of teachers and trainers; the cost of providing m-Learning devices and infrastructure; the slow rate 
of change in large educational institutions; and that mobile devices are not designed with the education market in mind.

With consumers driving the global uptake of mobile telephony, and the growing functionality of these devices, it appears that m-Learning does indeed have a place in mainstream education and training. Managing m-Learning as a part of a suite of services that offers greater choice to learners will have benefits for providers, because it can allow teachers to move from delivery to the management of learning, and will help learners to gain specific skills of immediate value in the knowledge-based economy.

\section{Acknowledgement}

Based on research undertaken by Kristine Peters entitled Learning on the Move: Mobile technologies in business and education, for the 2005 Australian Flexible Learning Framework. To read the full paper: http://www.flexiblelearning.net.au/projects/resources/2005/Research.htm

\section{References}

Aquino, M. (n.d.). Something to do, not something to learn: Experiential learning via online role play. Australian Flexible Learning Framework. Retrieved March 17, 2007 from: http://www.flexiblelearning.net.au/leaders/fl leaders/fll04/papers/reviewessay aquino.pd $\underline{\mathrm{f}}$

Bridgland, A., \& Blanchard, P. (2005). Powerful, portable, personal computing: Is m-learning an opportunity in e-learning? University of Melbourne. Retrieved March 17, 2007 from: http://eprints.infodiv.unimelb.edu.au/archive/00000889/01/bridgland.blanchard.pdf

Brodsky, M. (2003, May 7) E-learning Trends Today and Beyond. LTi Newsline. Retrieved March 17, 2007 from:

http://www.ltimagazine.com/ltimagazine/article/articleDetail.jsp?id=56219

Deviney, N., \& von Koschembahr, C. (2004, March 21). Learning goes mobile. Human Resource Executive. Retrieved July, 222005 from: http://www.workindex.com/editorial/train/trn0402-02.asp Editor's Note: This link no longer available, but it is cited in Keegan, D. (2005). Mobile Learning: The Next Generation of Learning, Distance Education International. Retrieved March, 172007 from: http://learning.ericsson.net/mlearning2/files/workpackage5/book.doc

Fannon, K. (2004). Connectedness: Learner perspectives on learning futures. Australian Flexibile Learning Network: Flex e-News Newsletter. Retrieved September, 272005 from: http://www.flexiblelearning.net.au/newsandevents/Flexenews/41/Kate_Res.pdf

Hartnell-Young, E., \& Jones, P. (2004, October 6). Mobile Law and e-Portfolios. The Knowledge Tree. Retrieved March 17, 2007 from http://knowledgetree.flexiblelearning.net.au/edition06/html/cr_elizabeth_hartnellyoung.html 
Klopfer, E., \& Squire, K., Jenkin, H. (n.d.). Environmental Detectives - The development of an Augmented Reality Platform for Environmental Simulations. Educational Research Technology and Development. Los Alamitos, CA.: IEEE Computer Society Publications.

Lundin, J., \& Magnusson, M. (2003). Collaborative Learning in Mobile Work. Journal of Computer Assisted Learning, 19(3), 273-283.

Peters, K., \& Lloyd, C. (2003). Differentiating Needs: Customer demand for online learning. The National Centre for Vocational Education Research (NCVER), Australian National Training Authority website. Retrieved March 17, 2007 from: http://www.ncver.edu.au/research/proj/nr2f02.pdf

Prensky, M. (2001, October). Digital Natives, Digital Immigrants. On The Horizon. NCB University Press, 9(5), October 2001. Retrieved March 17, 2007 from: http://www.marcprensky.com/writing/Prensky\%20\%20Digital\%20Natives,\%20Digital\%20Immigrants\%20-\%20Part1.pdf

Ragus, M. (2004a). Mobile Learning: handheld innovations in flexible learning - Case Studies. New Practices in Flexible Learning, Australian Flexible Learning Framework. Retrieved March 17, 2007 from: http://pre2005.flexiblelearning.net.au/projects/mobilelearning.htm

Ragus, M. (2004b). Mobile Learning: Handheld innovations in flexible learning. Project Report. New Practices in Flexible Learning, Australian Flexible Learning Framework. Retrieved March 17, 2007 from: http://pre2005.flexiblelearning.net.au/projects/mobilelearning.htm

Rheingold, H. (2002). Smart Mobs: The next social revolution. New York: Basic Books.

Rosenberg, M. J. (2001). E-learning: Strategies for delivering knowledge in the digital age. New York: MacGraw-Hill.

Smithers, R. (2003, October 16). Children Are Internet Experts. The Guardian online. Retrieved March 162007 from: http://education.guardian.co.uk/elearning/story/0,1064034,00.html

Spender, D. (2006, September 30). Personal communication with Dr. Dale Spender via telephone.

Zurita, G., \& Nussbaum, M. (2004). A constructivist mobile learning environment supported by a wireless handheld network. Journal of Computer Assisted Learning, 20, 235-243.

Retrieved May 24, 2007 from: http://www.blackwellsynergy.com/doi/pdf/10.1111/j.1365-2729.2004.00089.x?cookieSet=1 